\title{
SOBRE LA FUTURA *HISTORIA DE LA LENGUA DE MENÉNDEZ PIDAL
}

\author{
Francisco Abad \\ Uned \\ fabad@flog.uned.es
}

\begin{abstract}
Resumen
This article presents the published parts of the future Ramón Menéndez Pidal's Historia de la lengua española, and also makes reference to another Menéndez Pidal works related with the former book.

Likewise, we will talk about some theoretical notions on D. Ramón's linguistics as well as about his mentality thoroughly linked to krausism.
\end{abstract}

\section{Menéndez Pidal y sus discípulos, el krausismo, y el 98 y otras generaciones}

En las generaciones intelectuales de la España contemporánea, Menéndez Pidal pertenece obviamente -por la fecha de su nacimiento-a la del 98, así como sus discípulos Américo Castro, Dámaso Alonso o Rafael Lapesa pertenecen respectivamente a la del 14, la del 27. y la del 36. La pertenencia pidalina al noventayocho fue subrayada hace ya bastantes años por José Luis Abellán (1975: 256 y sigs.), quien luego ha vuelto al asunto (1989: 177-180); actualmente se subraya de nuevo tal pertenencia, pero ya vemos que se trata de un hecho que estaba bien establecido cuando se hace la historia de la cultura española.

Sin embargo lo que no debe olvidarse es que en don Ramón actuó en confluencia en parte con el noventayocho otra tradición de gran impronta: la del krausismo español. La impregnación krausista de la literatura de la segunda mitad del siglo XIX y del primer tercio del siglo XX es un hecho cierto -Ángel del Río lo advirtió alguna vez, y a sus párrafos preciosos remitimos (1963: II, 226-227)-, y en ese marco hay que situar asimismo a Menéndez Pidal: su austeridad personal de vida, la independencia de conciencia y un tono laicista, el gusto por las tradiciones y lo folclórico, la demofilia, etc., le inscriben en tal serie del krausismo español; de hecho la Junta para Ampliación de Estudios y el Centro de Estudios Históricos en los que tanto papel tuvo, eran instituciones llenas de ese espíritu krausista.

Nosotros formularíamos cómo Ramón Menéndez Pidal era persona de implantación krausista, pero que por su edad pertenecía a los hombres del 98 y ese noventayochismo incidió en su krausismo ${ }^{\prime}$. No es sin más un hombre del 98 , aunque también lo sea y le venga impuesto en parte forzadamente por su zona de fechas de nacimiento.

1 Entendemos ahora naturalmente por krausismo no una filosofia, sino una especie de ética más algunas doctrinas o actitudes como la de la sensibilidad demofilica, etc. 
Por lo que respecta no ya sólo a don Ramón sino a la escuela toda de sus discípulos y colaboradores directos, cabe repetir que son efecto cuatro generaciones de la cultura española -bien conocidas de los estudiosos-, las que han aportado nombres y hombres a la misma; hablamos de "generación" en sentido técnico, es decir (y de acuerdo con Ortega y Gasset), de comunidad de fecha y comunidad espacial, las cuales dan lugar a una "identidad de destino [que] produce en los coetáneos coincidencias secundarias" (Ortega y Gasset 1996: 87). Desde luego tenemos presente que la comunidad de fecha se produce según intervalos o cadencias de quince años: en el caso particular de nuestra cultura entendemos que la generación del noventayocho nace en los años que van de 1861 a 1875; la llamada generación del 14 entre 1876 y 1890; la del 27 de 1891 a 1905; y la del 36 entre 1906 y 1920.

En este sentido la nómina de miembros vinculados al Centro de Estudios Históricos es asi:

- generación del 98: Menéndez Pidal;

- generación de 1914: García de Diego, Navarro Tomás, Américo Castro, Federico de Onís, Homero Serís, Miguel Artigas, Eduardo Martínez Torner, Federico Ruiz Morcuende;

- generación del 27: Gili, Amado Alonso, Fernández Ramírez, Dámaso Alonso, Pedro Salinas, Antonio García Solalinde, Florentino Castro Guisasola, Miguel Herrero, José Fernández Montesinos, Ernesto Giménez Caballero;

- generación de 1936: Rafael Lapesa, Antonio Tovar, Vicente Llorens, Enrique Moreno Báez².

\section{Empresas colectivas del "centro" y obra pidalina}

La Memoria de la "Junta para Ampliación..." de 1912-1913 alude a "la obra de conjunto emprendida por la Sección", y que es la Colección de documentos lingüisticos de los siglos $X I \dot{a} X V$ : "casi todos los miembros del Centro -se nos apunta- [...] han aportado copias de documentos, cuyo estudio crítico está realizando D. R. Menéndez Pidal"; a estos Documentos, en fin, "seguirá [...] la Crestomatía literaria de la Edad Media". Vemos así con claridad hasta tres cosas: a) que se dibujan en el futuro los Documentos Lingüísticos del Reino de Castilla y los de Aragón; b) que otra empresa aparte será la Crestomatía; c) que se perfila asimismo la obra personal de don Ramón Origenes del español, ya que se halla estudiando la documentación allegada propia o ajenamente.

2 En cuanto a Rafael Lapesa, se consideraba a sí mismo afectiva y cordialmente un hermano menor de los hombres del 27, pero de acuerdo con los datos históricos objetivos hay que decir que pertenece a la llamada "generación de 1936", generación de importancia capital no tanto acaso en la literatura como en el desarrollo de las ciencias humanas en España (es la de Julián Marias, Pedro Laín, Julio Caro Baroja, José Ferrater Mora, Jaime Vicens Vives, José Antonio Maravall, Antonio Domínguez Ortiz, Enrique Gómez Arboleya,...). Los hombres del Veintisiete nacen entre 1891 (Pedro Salinas) y 1905 (Altolaguirre, Juan Larrea); Francisco Ayala, Lapesa, etc., son ya más jóvenes y pertenecen a otra generación de la cultura española.

Los hechos nos llevan de esta manera a no coincidir por tanto con el planteamiento que en su artículo necrológico "Lapesa, un lingüista de la generación del 27", hace J. L. Girón, y así se lo manifestamos por carta a nuestro colega. 
Menéndez Pidal sabido es que desde 1904 tenía publicado el Manual de gramática histórica, producto en definitiva bastante cercano a las concepciones generales de los neogramáticos, pero él, con la apelación a los factores geográficos e históricos, iba a falsar tal paradigma neogramático en escritos suyos ya de la segunda década del siglo XX y ejemplarmente en esa obra magna Origenes...

Y así en efecto la Memoria de la JAE relativa a 1924/26, además de incorporar a los nombres de los colaboradores del Centro el de Pedro Sánchez Sevilla, el ejemplar alumno de don Ramón que desapareceria pronto, da cuenta de la publicación del tomo primero de Origenes del español, e indica que el segundo "será un léxico de la lengua de los siglos X y XI", y que en la reunión de materiales "han trabajado don Pedro Sánchez Sevilla y don José [F.] Pastor"; asimismo está aludido el artículo de Amado Alonso "Español «como que» y «cómo que» (1925), presentado en tanto "un acabado estudio de sintaxis histórica" que en efecto constituye un análisis instructivo que no se incorporó luego a libro. En definitiva ocurre que a quien correspondió el trabajo principal del Glosario de voces usadas en el período de orígenes una vez desaparecido Sánchez Sevilla fue a $\mathrm{R}$. Lapesa, según indicaría en su momento el maestro gallego-asturiano; ese Glosario --en el que además han trabajado otras personas- va a editarse muy próximamente al cuidado de Manuel Seco y su equipo.

\section{El afán de una tarea}

La primera muestra amplia del deseo pidalino de hacer una Historia general de la lengua que es Historia externa pero no sólo externa, la tenemos en el conocido artículo suyo de Cruz y Raya "El lenguaje del siglo XVI" (1933); de hecho y por una alusión hecha una vez por el propio autor, sabemos que desde tal artículo y hasta el estallido de la guerra, no dejó de hacer a veces indagaciones y de tomar notas sobre la presente temática de una Historia de la lengua. Luego vendrán el cursillo de Cuba y su trabajo en Nueva York (en Columbia University), desde donde el 30 de Enero de 1938 le escribió a Georges Cirot al propósito y vamos a verlo.

Pero antes -según decimos- hubo un curso en Cuba del que cabe proporcionar una noticia. Efectivamente el 16 de Abril de 1937 don Ramón inauguró un curso en la Facultad de Filosofía y Letras de la Universidad de La Habana, y en tal ocasión leyó unas "palabras iniciales" que por fortuna se hallan publicadas y que hemos encontrado en revista. El Temario pidalino estuvo constituido por 12 enunciados de otras tantas lecciones, y a manera de inicio don Ramón sentó en efecto cómo

la historia de una lengua es en todos los casos expresión de la historia entera de un pueblo. En el caudal de voces y de giros que hoy todos empleamos están impresas las huellas del pasado[;] la tarea de la historia ha de ser hacernos conscientes de esas huellas, reconocer-

\footnotetext{
Ya una cuartilla autógrafa del joven Ramón relativa a sus "Planes" de trabajo (1901), registra el propósito de hacer una obra acerca de la "Historia del idioma español" junto a otra de "Gramática histórica del español" y una tercera dedicada a "El castellano en América" (Diego Catalán MMI: 16). Quizá por razones pedagógicas el texto que se adelantó fue el Manual de gramática histórica.
} 
las, interpretarlas. [...] El ahondar en la esencia del idioma no es un lujo superfluo de la ciencia, sino una necesidad de nuestro espíritu consciente (1937: 7) 4

En consecuencia, el maestro repasó sumariamente a continuación lo que la historia idiomática peninsular nos enseña acerca de nuestro pasado: presencia de lígures en España, sobre la romanización, carácter del establecimiento de los godos, "el enorme trabajo que el siglo XIII y luego el XV realizan para dotar a la lengua de un vocabulario científico y docto, del cual en gran parte hoy usamos", "las potentes influencias extranjeras en el idioma" [del siglo XVIII, etc.], la "rica diferenciación de variedades estilísticas" propia de las centurias últimas... (1937: 7-9). Y así sucesivamente.

Pero decíamos que desde Nueva York escribió don Ramón a Cirot unos meses más tarde, y entonces le exponía:

No puedo sentir otra satisfacción, y bien pobre es, que la de consumir los últimos años de la vida en servir a la cultura patria con aquello para lo que uno está preparado. Así trabajo febrilmente en adelantar una breve historia de la Lengua española. Privado de todos mis papeles preparatorios ( 30 años de trabajo que me han desaparecido) rehago como puedo las lecturas de autores y revistas hechas hace mucho y perdidas. Por fortuna las bibliotecas de aquí son muy buenas y dispongo de dos auxiliares que me facilitan el trabajo (citado en Catalán MMI: 233).

La continuidad en la tarea en estos años treinta es decidida: redactar en efecto una Historia del idioma patrimonial. Privado de momento de cualquier material, don Ramón debía rehacer su trabajo con la ayuda de la memoria y de las bibliotecas.

Los antiguos colaboradores del Centro sabían bien de la dedicación pidalina a los Documentos Lingüísticos del Reino de Castilla y a Origenes del español; le habían visto además hacer el escrito de Cruz y Raya, tomar notas para otros (entre esas notas algunas sobre la onomástica inspirada en el culto mariánico), etc.; tales colaboradores y discípulos veían pues a su maestro en tanto la persona que inigualadamente y mejor que nadie podía escribir la Historia del idioma, y así Américo Castro le escribió el 9 de Abril de 1943: "Es lástima que no haya dedicado V. todo su tiempo a la Historia del Español, porque eso es lo que nadie puede hacer sino V. [...] Ojalá veamos esa Historia" (citado asimismo en Catalán MMI: 259).

Unos dos meses y medio más tarde reincidía don Américo en decirle lo mismo a su maestro otra vez; sus palabras de entonces eran:

Insisto en que la gran urgencia es su Historia de la Lengua Española, tarea que ha de consumirle mucho tiempo y para la cual ha preparado tan preciosos materiales. Y la urgencia no viene de que tenga $V$. ya muchos años [...], sino de lo largo y complicado del trabajo, téngase la edad que se tenga ( $($ bid. .).

Vemos en efecto la imagen del estudioso que aparecía ante sus alumnos como quien podía llevar a cabo una tarea por la labor preparatoria previa, labor que se extendía ya en

4 En las siguientes págs. 236-238 figura el llamado "Temario" del curso, que tenemos recogido en Abad (2003: 82). 
el espacio de décadas; además se trataba de una empresa "larga y complicada", pues es mucho el estudio monográfico necesario: las lenguas prerromanas, la latinización peninsular y su carácter, la presencia del Islam, el período preliterario de orígenes, los grandes monumenros del castellano antiguo ("Cid", "Alejandro",...), la creación de la prosa, el retoricismo, etc., etc. La Historia de la lengua requiere para hacerla no sólo de una formación sólida y precisa en lingüística, sino de inacabables lecturas a lo largo de toda la cultura en castellano: por todo esto es tal trabajo tan complicado y largo ${ }^{5}$. Don Ramón, dentro de su tarea hercúlea, nada más llegó hasta hacia 1681 en esa Historia para la que tanto esfuerzo acumulaba.

A primeros de los años cuarenta don Américo se interesaba por el estado de los trabajos pidalinos para hacer su Historia del idioma, pero en realidad fue entre 1939 -luego de los ensayos previos, publicados o manuscritos en notas y papeletas- y 1942 cuando el maestro había dado "forma definitiva a buena parte de lo que había de ser la obra", según el testimonio de quien por vínculo familiar conoce como nadie sus papeles (Catalán 1974: 125).

Como referencia complementaria cabe recordar que durante la guerra y a estímulo de don Tomás Navarro, también Rafael Lapesa trabajó en hacer una Historia del idioma: así la "Biblioteca popular de cultura y técnica" de la Editorial Nuestro Pueblo anunció un tomito de Historia de la Lengua Española que con toda probabilidad debía ser el trabajo encargado al joven Lapesa; el libro aparecería en fin -y con más grandes pretensiones científicas- en 1942, según es sabido. Pero la Historia... de don Rafael requerirá otro análisis, que él mismo esbozó una vez.

En definitiva ocurre que redactada a fin de los años treinta y principios de los cuarenta y reescrita en parte y reorganizada luego en los mismos cuarenta, contamos con la Historia de la lengua pidalina que va de los tiempos prerromanos hasta Calderón y Antonio de Solís.

\section{Tradición y libertad expresiva en el lenguaje}

A la par y en esos primeros años cuarenta expuso Menéndez Pidal algunas concepciones generales suyas sobre el lenguaje; lo hizo en el discurso "La unidad del idioma", en el que proclamaba por ej. que la lengua consiste en una actividad de la libertad humana, aunque sujeta al todo social:

Un Schuchardt, un Bréal -escribió- combatían el concepto de la fatalidad en la evolución de las lenguas y el de la lingüística como ciencia de la Naturaleza, conceptos éstos que acabaron pronto por ser completamente abandonados, para sustituirlos por el de la lengua concebida como un hecho social, como una actividad espiritual humana (Menéndez Pidal 1966: 183).

La lengua es el ámbito de una libertad espiritual mediante la que los hablantes más afortunados se expresan con mejor éxito: don Ramón falsaba al mantener ideas así el fatalismo positivista de los neogramáticos, y de esta manera se sentía llevado al análisis de por ej. los gustos idiomáticos actuantes en el hablar común, los estilos literarios, etc.

5 Por ej., ¿quién sospecharía que para la documentación de galicismos (y de anglicismos) en la lengua patrimonial deben leerse las a veces muy largas novelas de "La ceniza fue árbol" de Ignacio Agusti? 
Nuestro autor consideraba que en efecto el lenguaje es un producto muy tradicional, muy arraigado por tanto en la comunidad hablante, y que a pesar de ello la innovación y el cambio idiomáticos poseen un origen individual. El peso del arraigo tradicional de las formas establecidas resulta desde luego muy poderoso, pues en otro caso se llegaría a la ininteligibilidad; ocurre pues que

cada hablante moldea los materiales que en su memoria ha depositado la tradición, los transforma ajustándolos al estímulo expresivo que le mueve a hablar, los vivifica dándoles una existencia singular que nunca tuvieron antes ni volverán a tener después jamás; pero a pesar de eso, la lengua permanece en su identidad esencial, pues el individuo crea su habla en continuo ajuste y contraste con la comprensión del oyente y con el uso general de los demás hablantes (Ibid.: 194).

La lengua consiste por tanto en una expresividad singular limitada por la necesidad de intercomprensión, limitada por su ineludible permanencia esencial; no obstante el papel del individuo no es mecánico sino que comporta el uso de su libertad. El mejor hablante es el que dentro de tal identidad ineluctable del idioma alcanza el mejor acierto expresivo, y en todo caso cualquier innovación que más tarde se consolide depende asimismo de su inicio en un individuo que luego se propaga y alcanza vigencia. Proclama en tal senrido don Ramón:

Los cambios que se produzcan en el lenguaje, siendo éste un hecho humano, serán siempre debidos a la iniciativa de un hombre, de un individuo que al desviarse de lo habitual, logra la adhesión o imitación de otros, y éstos logran la de otros; en suma el proceso de cualquier neologismo será idéntico al proceso por el que se propaga cualquier opinión o cualquier costumbre en un grupo humano hasta hacerse propia de la mayoría (Ibid.: 194-195).

Don Ramón hacía -según decimos- estas consideraciones a la vez que estaba dando cima a la extensa parte que escribió de su Historia de la lengua; estamos ante ideas arraigadas en el denominado idealismo lingüístico, y además puede registrarse que una concepción análoga del idioma la desarrollaría años más tarde Eugenio Coseriu en su incitante y muy brillante obra Sincronia, diacronia e historia.

[Digamos simplemente y a manera de complemento que en este discurso pidalino al que aludimos "La unidad del idioma", entra su autor en caracterizaciones específicas de la lengua patrimonial; delimita entonces "dos tipos de lengua española culta", y los deslinda según algunas peculiaridades de pronunciación, a saber:

Un tipo de español conserva más fielmente el valor etimológico de ciertos sonidos, sobre todo distinguiendo " $s$ " de " $z$ " y "ll" de " $y$ ", según el origen de las palabras en que esos sonidos se encuentran. El segundo tipo confunde las dos fricativas dentales en "s" (seseo), $y$ las dos palatales en " $y$ " (yeísmo). Y he aquí la complicación geográfica: el seseo caracteriza al español americano pero no es exclusivo de él, pues también se usa en gran parte de Andalucía. El yeísmo es general en Méjico y Centroamérica pero no en el Sur, donde pronuncian la "ll" Bolivia, Paraguay, gran parte de Colombia, de Ecuador, de Perú, de Chile y de la Argentina; en España se hallan muy entremezcladas las regiones de yeísmo con las de "Il". 
De esta manera "sólo aproximadamente" América representa el tipo fonético derivado, y asimismo sólo aproximadamente Castilla, León y Aragón realizan el tipo prosódico tradicional (Ibid:: 206-207)].

Don Ramón volvió a las presentes cuestiones teóricas algo más de una década más tarde (1957b: 364-371). Por otra parte y a propósito de esta Historia de la lengua pidalina y del manual de Lapesa coetáneo, el prof. Catalán ha glosado algo por lo demás evidente: que las "Historias de la lengua" del siglo XX "no podía[n] aceptar el nombre de «historia» para las fórmulas de las gramáticas diacrónicas", y que así la Historia de la lengua "sólo puede hacerse en constante referencia a la historia cultural de la comunidad" (Catalán 1974: 129130). Ciertamente las formulaciones del positivismo decimonónico se reducían a enunciados esquemáticos de hechos fonético-fisiológicos, etc., mientras la real situación del hablar es la de comunidades humanas específicas en la que interactúan factores de historia externa, diastráticos...

Además subraya Catalán otra verdad de sentido común filológico: que ha de hacerse una visión conjunta de todas las manifestaciones del idioma y que una de ellas es la literaria, por lo que importa asimismo el lenguaje de la literatura (Ibid.: 131). Nada más mutilador resultaría ciertamente dejar de lado las sucesivas creaciones de estilo -tantas y muchas veces tan logradas en la serie literaria castellana- que cabe registrar. Nadie puede imaginarse una Historia del idioma español que se halle falto de los capítulos (por ej.) de Garcilaso, de Góngora, de Ortega o Lorca, etc.

\section{Lo ya publicado de la *Historia...}

Don Ramón fue dando a luz en el último tercio de su vida muestras y adelantos de lo que iba a ser su Historia de la lengua, además de otros escritos hechos en la misma orientación o bien complementarios del trabajo principal. Además de "El lenguaje del siglo XVI", fragmentos directamente procedentes del manuscrito de la Historia creemos que fueron:

- “De Alfonso a los dos Juanes. Auge y culminación del didactismo" (1972).

- "La lengua en tiempo de los Reyes Católicos. Del retoricismo al humanismo" (1950).

- "Sevilla frente a Madrid" (1962)

- "El lenguaje español en tiempo de Felipe II" (1963).

- La lengua castellana en el siglo XVII (1991).

- "Onomástica inspirada en el culto mariánico" (1965).

Además y según es sabido don Ramón trató en Escorial de "El estilo de Santa Teresa", etc.

Menéndez Pidal se veía llevado naturalmente -pues- a ir dando a luz buena parte de lo que llevaba hecho acerca de la diacronía de la lengua en los primeros siglos modernos, quizá por variar respecto de las cuestiones medievales de épica en las que tanto trabajaba y 
también por ir completendo esa perspectiva medieval con la de lo que alguna vez denominó "nuestra edad de oro literaria". No obstante nuestro autor dejó la Historia del idioma que estaba haciendo aproximadamente en el momento de la muerte de Calderón.

Evidentemente el hacer unos trabajos impide poder hacer otros, y así al maestro le faltó holgura temporal para volver a las muchas páginas que ya tenía escritas. Pero Diego Catalán apunta a otras razones complementarias para que la Historia del español quedase inacabada:

De esta postergación de sus principales obras fue sin duda causa principal un afán, desarrollado en sus años de retiro en la Cuesta del Zarzal, de "saberse vivo", de formar parte del presente cultural, afán que le hacía atender constantemente peticiones de colaboración extemporáneas (MMI: 335).

En verdad a la psicología del investigador le ocurre así, que atiende asuntos que no son a veces aquellos en los que puede dar más alta talla, bien por peticiones y encargos ajenos a él, bien por propio gusto o necesidad psicológicos. Hay muchos ejemplos que lo demuestran, y ocurre en particular en los temperamentos que la caracteriología tipifica como "sentimentales", que suelen ser emotivos y no activos.

Pero según hemos apuntado en otras ocasiones, hay una razón de relieve que explica el desapego de nuestro autor a los siglos más recientes. Menéndez Pidal participa de una historiografía de carácter romántico que en cuanto tal hace particular estimación de la Edad Media y de los héroes (en este caso el Cid), y asimismo de una historiografía nacionalista que exalta las glorias pretéritas, las glorias del pasado español sobre todo del Quinientos. Don Ramón se ocupó así -por diversas razones convergentes- de los tiempos españoles medievales y áureos, y también por esta razón dejó inacabada su Historia idiomática castellana.

\section{Fenómenos lingüísticos en el seiscientos}

La Historia de la lengua española pidalina acaba según sabemos ya con las referencias al habla común del siglo XVII, pero además don Ramón o su discípulo Rafael Lapesa no dejaron de aludir expresamente a esta habla común seiscentista en algunos escritos monográficos suyos.

El maestro gallego-asturiano habló por ej. de que el intercambio entre los dos sufijos -ano, -an y -en perduraba todavía en la lengua muy vulgar del siglo XVII, y de esta forma nos lo asegura para la región de Niebla (Huelva) el testimonio de Mateo Alemán, a saber: "Vi que muchos llamaban escrivén a el escribano"; nos lo asegura asimismo Tirso, quien repite mucho tal forma escribén en tanto vocablo típicamente rústico;... Y así sucesivamente (Menéndez Pidal 1968: 156-158).

Otro caso de la lengua común seiscentista notado por don Ramón es el que queda registrado en el $\S 107$ del Manual de gramática histórica...: las formas esdrújulas amábades, fariades mantienen la $-d$ - hasta ese siglo XVII. El autor remite de manera expresa entonces a la Nota 90 puesta por Cuervo a la Gramática... de Bello, en la que en efecto podemos leer:

Las inflexiones esdrújulas persistieron intactas por más tiempo; [...] insensiblemente fueron generalizándose, y aunque rarísimas todavía en las obras de Cervantes y de Lope, es de creerse que al fin de su siglo la generación joven ya no las empleaba, por más que 
Calderón se sirviese todavía de ellas en su última comedia (1680). En estilo cancilleresco subsistieron hasta bien entrado el siglo siguiente.

Ciertamente a la vista del presente hecho y de otros más analizados por Amado Alonso, C. Company, etc., creemos nosotros que cabe mantener que el español clásico es ya español moderno a partir de la época que proponemos delimitar entre 1648 (obras maduras de Gracián) y 1680. Se ve además el complicado tejido de isoglosas en que también diacrónicamente consiste el hablar: la cronología de las innovaciones y de su difusión de entrecruza en la dimensión del tiempo, pues cada fenómeno posee unas fechas, y es lo que ocurre ciertamente en el caso de las desinencias esdrújulas que acabamos de ver.

Don Ramón advirtió asimismo el incremento de la onomástica marial en el siglo XVII, en dependencia -razonaba- de la Contrarreforma; se trata de una onomástica que especifica los misterios de la vida de la Virgen (cfr. Menéndez Pidal 1965). Por ej. nuestro autor tiene escrito:

En las parroquias de los barrios más aristocráticos de Sevilla y de Madrid se registran sendos bautizos con el nombre de María de la Concepción en dos niñas nacidas en días próximos a la fiesta de la Inmaculada de los años 1615 y 1616 respectivamente, nombre que no tarda en hacerse muy corriente.

A su vez en la conocida parroquia de San Ginés de Madrid se hallan María de las Candelas en 1600, Maria de la Encarnación en 1613, Maria de la Asunción en 1615, y más tarde en el mismo Madrid encontramos María de la Presentación en 1625, María de la Visitación ya en 1664 , etc.

De la segunda mitad del XVII data en fin según los testimonios pidalinos "el uso de advocaciones tomadas de santuarios o imágenes veneradas": María del Carmen, del Pilar, de Loreto, de Atocha, de Guadalupe,...

Rafael Lapesa a su vez insistió en su día en cómo la forma usted tiene su primera muestra conocida en 1620, y en cómo su difusión se incrementó concomitantemente "con la ola de plebeyez y chabacanería que invadió la sociedad española en los últimos decenios de aquel siglo y primeros del XVIII" (Lapesa 2000: 317 y sigs.).

\section{La investigación pidalina en diacronía del idioma}

Además de la parte expresamente escrita para su Historia de la lengua española que conocemos en anticipo, la gigantesca obra entera pidalina consta de libros y escritos en los que se halla hecha asimismo nuestra historia idiomática. En cuanto a los tiempos primitivos contamos con el volumen de Toponimia prerrománica..., en el que por ej. se nos muestra cómo los nombres toponímicos nos aseguran la presencia de lígures o ambrones en el suelo peninsular junto a los íberos y los celtas: hay que admitir así la inmigración de este pueblo centroeuropeo ya en parte indoeuropeizado, que se extendió "por todo el noroeste de España": "poblaron bastante densamente el norte de Portugal, la Galicia, Asturias y la parte occidental de León" (Menéndez Pidal 1968: 103-104, 177-178, etc.).

A las voces de las lenguas prerromanas se refiere nuestro autor en el extenso $\S 4$ del Manual de gramática histórica...; la acción del substrato la aborda en Origenes... $\$ \S 41 \mathrm{y}$ 45-46. 
A "Hispania, provincia del Imperio Romano. Su personalidad", dedicó don Ramón unas páginas (Menéndez Pidal 1957a: I, 131-173) ${ }^{7}$. Más en concreto sobre el latín vulgar algunos datos esenciales los trae asimismo el Manual..., $\S 2$, así como hay muchas otras observaciones por todas partes del mismo libro; las relaciones del dialectalismo peninsular con el del Sur de Italia aparecen estudiadas en los $\S \S 52-55$ bis de Origenes.

Con carácter general sobre "Universalismo y nacionalismo. Romanos y Germanos", nuestro autor escribió asimismo unas páginas (Menéndez Pidal 1957a: I, 175-238); los elementos léxicos germánicos aparecen en el mismo $§ 4$ del Manual..., y la "época visigótica" en la formación de nuestra lengua se halla caracterizada en Origenes..., $\S 103$. Para los godos y la totalidad de siglos altomedievales léase asimismo el libro pidalino de 1992, que incluye también observaciones idiomáticas8.

Nuestro autor gustaba de los grandes asuntos de una Historia universal, y de esta manera escribió asimismo páginas generales sobre "Cristiandad e Islam" (Menéndez Pidal 1957a: I, 349-356); el Manual... alude a los arabismos léxicos ( $\$ 4.4)$, y lo mozárabe y los mozárabes se hallan muy presentes en bastantes momentos de Origenes del español, además de en los escritos propios que estudiaron la lírica primitiva. Todo el "Centro de Estudios Históricos" tuvo como propósito de importancia el análisis de la cultura mozárabe.

A partir del momento de la arabización peninsular bien sabido es que Ramón Menéndez Pidal analizó inigualadamente todos los siglos de orígenes próximos de la lengua, y luego tanto el llamado Cantar de Mio Cid (en realidad "Poema" con varios cantares) como La España del Cid. El dialectalismo de la literatura antigua no escapó a nuestro autor, tanto al abordar el poema cidiano como al analizar otros más: "Roncesvalles", "Elena y María", etc. (Menéndez Pidal 1976: passim).

Observaciones sobre los textos literarios clericales hay en el texto pidalino que trata de la Poesia juglaresca (1957b: 272 y sigs.), y más adelante en los tiempos, quedan registrados ya los sucesivos anticipos con que contamos de la *Historia de la lengua española pidalina. Nada conocemos todavía sin embargo -escribimos en la segunda mitad de Agosto de 2003-, de lo que redactó acerca de la diacronía idiomática entre la segunda mitad del siglo XIV y el inicio del reinado de los Reyes Católicos; es época sin embargo muy frecuentada por la atención estudiosa de Rafael Lapesa, y por la enorme capacidad investigadora que poseyó inigualadamente María Rosa Lida9.

En lo que conocemos que ha escrito acerca del Quinientos, Menéndez Pidal no se detiene en la lengua literaria de la novela pastoril; sobre el lenguaje literario del Barroco -conociendo ya lo escrito por nuestro autor-, puede decirse que seguramente Lope de Vega requiere mayor atención: su obra tan extensa y de tanta variedad requerirá sin duda de nuevos aná-

7 La presente obra a la que remitimos España y su historia es en buena parte antológica, por lo que muchas de sus páginas se hallan impresas asimismo una o varias veces más.

8 Sistematiza de nuevo por ej. don Ramón cómo la -e llamada paragógica "no es licencia poética de paragoge [...]; es etimológica", y alude al nombre de "Casrilla", sobre el que escribe que "suena por primera vez en los documentos hoy conocidos en el año 800 [...], designando un pequeño territorio extendido al sur de los montes de Trasmicra (Santander) hasta incluir el valle del Ebro al norte de la cordillera de los montes Obarenes, la del desfiladero de Pancorvo, que defendía de los ataques del sur aquel territorio. Era nombre reciente en el siglo IX, pues antes a esa C a s t e 11 a se la llamaba V a r d u 1 i a" (1992: 191, 373).

9 Quizá no resulta azaroso que la mayor dedicación a los años 1350-1474 por parte de Lapesa se corresponde con la menor dedicación a los mismos por parte de Menéndez Pidal: las obras de uno y otro se complementan y completan así. 
lisis. En la lengua seiscentista la de Lope es quizá la que -en el estado actual de la investigación- mayor trabajo requiere aún. Asimismo la primera época gongorina apenas si la aludió don Ramón, que sin embargo dedicó amplio espacio a la polémica estético-lingüística de las Soledades e hizo separadamente el artículo específico sobre el asunto "Obscuridad, dificultad entre culteranos y conceptistas" (en el mismo vol. de 1966: 217-230).

Una mentalidad nacionalista como la pidalina, y gustosa además de la llamada "naturalidad" y de la claridad elocutivas -huellas ambas de su maestro Menéndez Pelayo-, tenía que valorar mucho la época de la segunda mitad del siglo XVI; coincidía además con el momento que él mismo calificaba como de "aspiración a una norma lingüística nacional". Así don Ramón estima mucho estos años de Felipe II, y piensa que su lengua escrita fue "la modalidad más hermosa que jamás se escribió en España" (debemos entender quizá "la modalidad... que se había escrito hasta entonces... ').

Menéndez Pidal detuvo su obra de conjunto tras la muerte de Calderón, y ya quedan expuestas algunas de las razones ${ }^{10}$; nos queda a los demás completar el análisis general de la trayectoria de los siglos siguientes, como queda asimismo prolongar hasta nuestro tiempo la Historia de las ideas estéticas de Menéndez Pelayo. No obstante, breves indicaciones sobre la prosa de Jovellanos o Moratín y el Conde de Toreno se encuentran en la Antología de prosistas españoles (1932).

\section{Menéndez Pidal y Rafael Lapesa}

La edición definitiva de la Historia de la lengua española de Rafael Lapesa contiene probablemente más datos de lingüística interna que los que tendrá la pidalina, y ello se debe al propio estilo intelectual del maestro gallego-asturiano, más gustoso que don Rafael de los estudios históricos generales y que por ej. dedicó amplio espacio a tratar de la polémica gongorina, asunto en el que no entró nunca Lapesa. Además hay que notar que algunas monografias específicas sobre el lenguaje literario del mismo don Rafael, no quedaron recogidas en una abreviatura y en sus resultados en su Historia dela lengua.

Se asemejan ambas Historias en prestar menor atención (o no prestarla) a lo posterior a 1680: en Lapesa debió operar el antecedente pidalino, así como algunas de las otras causas que incidieron en don Ramón.

En cuanto a datos de esa llamada "lingüística interna" sabido es que Lapesa prolongó algunas observaciones pidalinas sobre la apócope medieval, e incidió junto con el maestro en la temática del andaluz y del español en América; asimismo D. Catalán volvió en varios estudios a las mismas cuestiones.

\section{Palabras finales}

La persona y la obra toda de don Ramón Menéndez Pidal resultaron ejemplares. La liberalidad de ánimo, su entronque con lo mejor de la cultura española contemporánea (el ejemplo a su vez de Menéndez Pelayo, la vinculación a la mentalidad krausista y su esti-

10 En Menéndez Pidal 1957b: vol. II, se encuentra una amplia antología (como queda dicho) de escritos y fragmentos suyos referidos ahora a los tiempos modernos e incluso a los contemporáneos. La presente obra España y su historia quiso ser en efecto una muestra orgánicamente preparada de la interpretación de nuestro autor en cuanto a lengua, literatura e historia de España; es lástima que tales dos volúmenes hayan pasado un tanto inadvertidos. 
mación así de las tradiciones, de lo popular,...), la dedicación ascética al trabajo, su ingente producción escrita, hacen de don Ramón una de las figuras más logradas de toda la historia contemporánea española.

Creador de escuela, sus discípulos inmediatos más representativos han alcanzado a hacer asimismo una obra personal de importancia por igual decisiva, desde don Tomás Navarro y los dos Alonsos a Fernández Ramírez, Gili Gaya, y los más cercanos en el tiempo Rafael Lapesa, Álvaro Galmés y Diego Catalán.

La futura *Historia de la lengua española del maestro constituirá una aportación fundamental a los estudios de humanidades en España, y perdurará en su concreta factura al igual que el Manual de gramática histórica, Orígenes del español, y los magnos tratados pidalinos acerca de la épica y el romancero. Non omnis moriar.

\section{Referencias bibliográficas}

Abad, F. (2003): "Lengua Española". Para la historia de un concepto y un objeto. Murcia, Universidad.

Abellán, J. L. (1975): La industria cultural en España. Madrid, Edicusa.

Abellán, J. L. (1989): Historia crítica del pensamiento español, vol 5/2. Madrid, Espasa-Calpe.

Alonso, A. (1925): "Español «como que» y «cómo que»", RFE, XII, págs. 133-156.

Catalán, D. (1974): Lingüistica Íbero-románica. Madrid, Gredos.

Catalán, D. (MMI): El archivo del romancero. Madrid, Fundación Ramón Menéndez Pidal.

Lapesa, R. (2000): Estudios de morfoxintaxis histórica del español. Madrid, Gredos.

Menéndez Pidal, R. (1932): Antología de prosistas españoles. Edición definitiva, Madrid, Junta para Ampliación de Estudios.

Menéndez Pidal, R. (1933): “El lenguaje del siglo XVI", Cruz y Raya, 6, págs. 7-63.

Menéndez Pidal, R. (1937): "Palabras iniciales de un curso", Revista Cubana, VIII, números 22-24, págs. 5-9.

Menéndez Pidal, R. (1950): "La lengua en tiempo de los Reyes Católicos. Del retoricismo al humanismo", Cuadernos Hispanoamericanos, 13, págs. 9-24.

Menéndez Pidal, R. (1957a): España y su historia. Madrid, Minotauro.

Menéndez Pidal, R. (1957b): Poesía juglaresca y origenes de las literaturas románicas. Madrid, Instituto de Estudios Políticos.

Menéndez Pidal, R. (1962): "Sevilla frente a Madrid". En Catalán, D. (ed.): Estructuralismo e historia. La Laguna, Universidad, vol. III, págs. 99-165.

Menéndez Pidal, R. (1965): "Onomástica inspirada en el culto mariánico", Cuadernos del idioma, I/1, págs. 9-16.

Menéndez Pidal, R. (19664): "La unidad del idioma". En su vol. Castilla. La tradición, el idioma. Madrid, Espasa-Calpe, págs. 169-215.

Menéndez Pidal, R. (1968): Toponimia prerrománica hispana. Madrid, Gredos (reimpresión).

Menéndez Pidal, R. (1972): "De Alfonso a los dos Juanes. Auge y culminación del didactismo (1252-

1370)". En Studia hispanica in honorem R. Lapesa. Madrid, Gredos, vol. I, págs. 63-83.

Menéndez Pidal, R. (1976): Textos medievales españoles. Madrid, Espasa-Calpe.

Menéndez Pidal, R. (1991): La lengua castellana en el siglo XVII. Madrid, Espasa-Calpe.

Menéndez Pidal, R. (1992): La épica medieval española. Desde sus orígenes hasta su disolución en el romancero. Madrid, Espasa-Calpe.

Ortega y Gasset, J. (1996): En torno a Galileo. Madrid [ed. de Abellán, J. L., según la de Garagorri, P.], Espasa Calpe.

Río, A. del (1963): Historia de la literatura española. New York, Holt, Rinehart and Winston. 